\title{
The influence of testosterone suppression on HER2 immunoexpression in prostatic neoplastic tissue
}

\author{
GUILHERME ANDRADE PEIXOTO ${ }^{1,2}$, FERNANDO KORKES ${ }^{1,2}$, CRISTIANO LINCK PAZETO ${ }^{1,2}$, \\ MARILIA GERMANOS DE CASTRO ${ }^{3}$, THIAGO FERNANDES NEGRIS LIMA ${ }^{1}$, \\ MARCELO LANGER WROCLAWSKI ${ }^{2,4}$, NICOLLE MARTIN CHRISTOFE ${ }^{1,5}$, MARCOS TOBIAS-MACHADO ${ }^{1}$, \\ LUCILA HELOISA SIMARDI SANTIAGO ${ }^{1}$ and SIDNEY GLINA ${ }^{1,2}$ \\ ${ }^{1}$ Department of Urology, Centro Universitário FMABC, Santo André, São Paulo 09060-870; ${ }^{2}$ Department of Urology, \\ Hospital Israelita Albert Einstein, São Paulo 05652-900; ${ }^{3}$ Department of Pathology, Hospital Sírio-Libanês, \\ São Paulo 01308-050; ${ }^{4}$ Department of Urology, Beneficência Portuguesa de São Paulo, São Paulo 01323-001; \\ ${ }^{5}$ Department of Urology, Faculty of Ciências Médicas da Santa Casa de São Paulo, São Paulo 01238-010, Brazil
}

Received February 26, 2020; Accepted May 17, 2021

DOI: $10.3892 / \mathrm{mco} .2021 .2347$

\begin{abstract}
During initial risk assessments, the metastatic potential of prostate cancer (PCa) may not be fully considered. The tumor's multicentric origin, which is associated with genetic mutations, may explain existing treatment limitations. Investigating human epidermal growth factor receptor 2 (HER2) expression in patients with different stages of PCa may therefore increase understanding of the mechanisms associated with the development of castration resistance. The present study examined the association between HER2 expression and the histologic features of PCa subjected to radical prostatectomy (RP) and evaluated the role of testosterone suppression in HER2 expression. In group 1, specimens from individuals who underwent RP without prior neoadjuvant androgen deprivation therapy (ADT) were included $(n=42)$. In group 2 (PCa with ADT), specimens from individuals who underwent RP and received neoadjuvant cyproterone acetate during distinct periods (200 mg daily for 1-24 months) were included $(n=150$; cohort derived from a previous study). Immunohistochemical expression of HER 2 was associated with prognostic factors such as perineural invasion, extra-prostatic disease, $\mathrm{T}$ stage, serum prostate-specific antigen (PSA), angiolymphatic invasion and surgical margins. Univariate regression analysis indicated that perineural invasion, PSA, International Society of Urological Pathology, angiolymphatic invasion, margin, $\mathrm{T}$ stage and neoadjuvant ADT was associated with HER2 expression. Ordinal regression analysis indicated a significant effect of
\end{abstract}

Correspondence to: Dr Guilherme Andrade Peixoto, Department of Urology, Centro Universitário FMABC, 821 Príncipe de Gales Avenue, Santo André, São Paulo 09060-870, Brazil

E-mail: gui_peixoto@hotmail.com.br

Key words: biomarkers, Gleason score, HER2, prostate cancer, prostate-specific antigen, immunohistochemistry neoadjuvant ADT alone on HER2 expression $(\mathrm{P}<0.001)$. In addition, regression analysis indicated a significant effect of neoadjuvant ADT alone on HER2 expression (odd ratio=0.01; 95\% CI, 0.00, 0.02; P<0.001). HER2 was expressed in $\mathrm{PCa}$ samples but was not associated with known prognostic factors. The use of short-acting ADT and the consequent blockage of testosterone effect may suppress the expression of HER2 in PCa cells.

\section{Introduction}

The human epidermal growth factor receptor 2 (HER2) oncogene encodes a transmembrane protein (17q12-21.32) with tyrosine kinase activity, which acts as a growth factor (1). HER2 has been detected with variable expression in a wide variety of malignant tumors and has been found to be an adverse prognostic marker in breast $(20 \%)$ and ovarian $(33 \%)$ adenocarcinomas $(2,3)$. Overexpression of the HER2 protein and amplification of the HER2 gene, or both, occurs in approximately $25 \%$ of breast cancers and is associated with aggressive behavior (4).

Although unequivocal data on HER2 overexpression are not available for prostate cancer (PCa), evidence suggests that it may be crucial for disease progression and aggressiveness (5). A recent study supporting these findings was a comprehensive immunohistochemical (IHC) evaluation of 2,525 samples, which revealed positive associations between HER2 staining, PCa aggressiveness, and recurrence (6). In addition, high levels of HER2 have been correlated with tumor growth in LAPC-4 androgen-independent PCa cells (7). Furthermore, HER2-dependent signaling may support the development of castration-resistant PCa (CRPC) through androgen ligand-independent mechanisms (8).

However, there are no available data on the influence of castration on HER2-dependent signaling in patients with castration-sensitive PCa. Investigating the expression of HER2 in patients undergoing hormonal therapy during distinct periods could also increase our understanding of the 
mechanisms associated with the development of castration resistance.

The metastatic potential of PCa may not be fully understood during the initial risk assessment (9). The tumor's multicentric origin, associated with genetic mutations, may explain treatment pitfalls $(10,11)$.

Our research had two objectives: To correlate HER2 expression with the histologic features of PCa subjected to radical prostatectomy (RP) and to evaluate the role of testosterone suppression in HER2 expression.

\section{Materials and methods}

Patients. RP specimens were obtained from patients who were consecutively treated at two different institutions from 1998 to 2011 (Santa Casa of São Paulo Hospital and Centro Universitário FMABC Hospital). The local ethics committee approved the study (84427718.0.0000.0082 and 06937412.0.1001.0082).

Formalin-fixed paraffin-embedded (FFPE) tissue blocks of tumor samples were identified and divided into two groups. group 1 included specimens from individuals who underwent RP without prior neoadjuvant androgen deprivation therapy (ADT) $(n=42)$. group 2 (PCa with ADT) included specimens from individuals who underwent RP after receiving neoadjuvant cyproterone acetate during distinct periods $(200 \mathrm{mg}$ daily for $1-24$ months) $(n=150$; cohort derived from a previous study) (12).

The patients in group 2 were those who were included in a study performed in 2014, which proposed hormonal therapy with neoadjuvant cyproterone before RP. The material was preserved in a paraffin block using the tissue microarray (TMA) technique for future studies. We chose to use this cohort because neoadjuvant cyproterone is not used today. Furthermore, it is not ethical to suppress testosterone for long periods of time in men who would undergo radical treatment.

All hematoxylin and eosin (H\&E)-stained histological sections from the RP specimens were reviewed. An index tumor (highlighted on the slides) was defined as the focus with the highest Gleason pattern or the largest tumor (in case of a single pattern). Other prognostic factors evaluated were perineural invasion, extra-prostatic disease, $\mathrm{T}$ stage, serum prostate-specific antigen (PSA), angiolymphatic invasion, and surgical margins.

Immunohistochemistry. In group 1, four to ten tissue sections (4 $\mu \mathrm{m}$ thick) were collected from the index tumors and mounted on glass slides. In group 2, two to four tissue sections (6 $\mu \mathrm{m}$ thick) were mounted on glass slides from the TMA block, as previously described (12). Histological sections from breast carcinoma cases were used as reference patterns for the positive reactions. Non-neoplastic breast and prostatic tissues (from an internal sample) were used for negative reactions.

Anti-HER2 antibody A0458, a polyclonal rabbit anti-human c-erbB-2 oncoprotein antibody (Dako $\mathrm{GmbH}$, Jena, Germany), was used (incubated at 1:600) for staining in tissue samples with distinct loss of basal cells (proven $\mathrm{PCa}$ ). The sections without any previous confirmation of $\mathrm{PCa}$ were not tested. Antigen recovery was performed according to the HercepTest ${ }^{\mathrm{TM}}$ manual (Dako) (13). The diluted epitope recovery solution $(1: 10)$ was preheated in a tank at $85^{\circ} \mathrm{C}$ and sections were dewaxed at room temperature and immersed in a preheated epitope recovery solution. They were heated to $97^{\circ} \mathrm{C}$ and incubated for $40 \pm 1 \mathrm{~min}$ at $97^{\circ} \mathrm{C}$. They were then left in the tank until they reached a temperature of $85^{\circ} \mathrm{C}$. They were then removed from the tank and left on the table with the lid closed for subsequent cooling. After $10 \mathrm{~min}$, the tissue sections were washed with diluted Dako wash buffer and soaked in this buffer for 5-20 min after epitope recovery and before staining.

All tissue sections were reviewed by two board-certified genitourinary pathologists (LHSS and MGC). All features were scored according to the Food and Drug Administration (FDA) and HercepTest ${ }^{\mathrm{TM}}$ manual interpretation (Dako) (13), which comprised intensity, percentage, and characteristics of the stain (from 0 to $3+$ ), and then the calculation of a final expression score. The immunohistochemical expression of HER2 was correlated with prognostic factors. The Gleason score was reclassified according to the International Society of Urological Pathology standards for (14). T staging was assessed using the clinical tumor node metastasis (TNM) classification standard (15).

Statistics. The data were analyzed using STATA 14.0 (StataCorp LP). Frequency tables were selected for descriptive analyses. Chi-square and Fisher's exact tests were used to assess the frequency of responses between the groups. For continuous variables, we used the Mann-Whitney test. In addition, logistic regression and ordinal logistic regression were applied to investigate the effect of covariates on the expression of the HercepTest ${ }^{\mathrm{TM}}$. Statistical significance was set at $\mathrm{P}<0.05$.

\section{Results}

Technical issues. A total of 192 men were included in this study. After analysis, 42 patients remained in group 1 and 104 in group 2. Due to unequivocal cancer tissue in the corresponding TMA section (remaining 104 samples), 46 samples were excluded from group 2. The proportion of non-interpretable samples for HER2 immunohistochemistry was $23.9 \%$.

Immunohistochemistry. The demographic characteristics of the patients are shown in Table I. The mean age was 66 years (interquartile range, 61-80 years). The mean PSA level in the study was $11.78 \pm 12.4 \mathrm{ng} / \mathrm{ml}( \pm \mathrm{SD})$. group 2 presented higher PSA levels compared to group $1(7.54 \pm 2.70 \mathrm{ng} / \mathrm{ml} \mathrm{vs}$. 13.49 $\pm 14.27 \mathrm{ng} / \mathrm{ml} ; \mathrm{P}=0.0021)$.

HER 2 expression was observed in $85.7 \%$ of specimens in group 1 and only in $1 \%$ of group 2 (Table II) (Fig. 1). Fig. 2 shows the expression of HER2 over time. In group 2, HER2 expression was subdivided into periods of exposure to hormonal therapy with cyproterone. Even after short periods of exposure to therapy, its expression was completely suppressed. While the cancer was sensitive to hormone therapy, HER2 expression was not detected (Fig. 2).

When considering only patients without neoadjuvant ADT (group 1), univariate regression analysis showed an association between ISUP and HER 2 expression $(\mathrm{P}=0.018)$. However, multivariate regression analysis showed that perineural invasion, PSA, ISUP, angiolymphatic invasion, positive 
Table I. Baseline characteristics and outcomes for all patients.

\begin{tabular}{|c|c|c|c|c|}
\hline Variable & Total N (\%) & group $1 \mathrm{~N}(\%)$ & group $2 \mathrm{~N}(\%)$ & P-value \\
\hline Perineural invasion & & & & 0.004 \\
\hline Yes & $63(43.15)$ & $26(61.90)$ & $37 \quad(35.58)$ & \\
\hline No & $83(56.85)$ & $16(38.10)$ & $67 \quad(64.42)$ & \\
\hline HER 2 expression & & & & $<0.001$ \\
\hline $2+/ 3+$ & $14(9.59)$ & $14(33.33)$ & $0 \quad(0.00)$ & \\
\hline $0 / 1+$ & $132(90.41)$ & $28(66.67)$ & $104(100.00)$ & \\
\hline ISUP & & & & 0.001 \\
\hline $1-2$ & $105(71.92)$ & $22(52.38)$ & $83 \quad(79.81)$ & \\
\hline $3-5$ & $41(28.08)$ & $20(47.62)$ & $21 \quad(20.19)$ & \\
\hline Angiolymphatic invasion & & & & 0.001 \\
\hline Yes & $30(20.55)$ & $16(38.10)$ & $14(13.46)$ & \\
\hline No & $116(79.45)$ & $26(61.90)$ & $90(86.54)$ & \\
\hline Surgical margins & & & & $<0.001$ \\
\hline Yes & $28(19.18)$ & $18(42.86)$ & $10(9.62)$ & \\
\hline No & $118(80.82)$ & $24(57.14)$ & $94(90.38)$ & \\
\hline T stage & & & & $<0.001$ \\
\hline $\mathrm{T} 1-\mathrm{T} 2 \mathrm{a}$ & $28(19.18)$ & $4 \quad(9.52)$ & $24(23.08)$ & \\
\hline $\mathrm{T} 2 \mathrm{~b}$ & $35(23.97)$ & $3(7.14)$ & $32(30.77)$ & \\
\hline$\geq \mathrm{T} 2 \mathrm{c}$ & $83(56.85)$ & $35(83.33)$ & $48(46.15)$ & \\
\hline Diabetes & & & & 0.105 \\
\hline Yes & $7 \quad(4.79)$ & $4 \quad(9.52)$ & $3 \quad(2.88)$ & \\
\hline No & $139(95.21)$ & $38(90.48)$ & $101(97.12)$ & \\
\hline Hypertension & & & & 0.001 \\
\hline Yes & $39(26.71)$ & $19(45.24)$ & $20(19.23)$ & \\
\hline No & $107(73.29)$ & $23(54.76)$ & $84(80.77)$ & \\
\hline Smoking & & & & 0.413 \\
\hline Yes & $16(10.96)$ & $6(14.29)$ & $10(9.62)$ & \\
\hline No & $130(89.04)$ & $36(85.71)$ & $94(90.38)$ & \\
\hline Ethnicity & & & & $<0.001$ \\
\hline White & $99(67.81)$ & $19(45.24)$ & $80(76.92)$ & \\
\hline Black & $6 \quad(6.16)$ & $4 \quad(9.52)$ & $5 \quad(4.81)$ & \\
\hline Mixed ethnic ancestries & $38(26.03)$ & $19(45.24)$ & $19(18.27)$ & \\
\hline Age $(\text { years })^{\mathrm{a}}$ & $64.88 \pm 6.75(66.00)$ & $64.48 \pm 7.42(64.50)$ & $65.04 \pm 6.48(66.00)$ & 0.729 \\
\hline $\operatorname{PSA}(\mathrm{ng} / \mathrm{ml})^{\mathrm{a}}$ & $11.78 \pm 12.41(8.55)$ & $7.54 \pm 2.70(7.15)$ & $13.49 \pm 14.27(9.70)$ & 0.002 \\
\hline
\end{tabular}

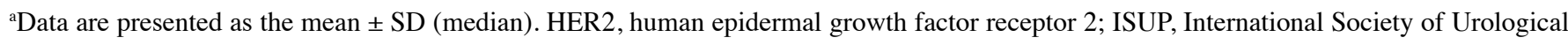
Pathology; PSA, prostate-specific antigen.

Table II. Distribution of HER2 expression in each group $(\mathrm{P}<0.001)$.

\begin{tabular}{|c|c|c|c|}
\hline HER2 expression & group $1 \mathrm{~N}(\%)$ & group $2 \mathrm{~N}(\%)$ & Total N (\%) \\
\hline 0 & $6 \quad(14.29)$ & 103 (99.04) & 109 (74.66) \\
\hline $1+$ & $22(52.38)$ & $(0.96)$ & $(15.75)$ \\
\hline $2+$ & $14 \quad(33.33)$ & $(0.00)$ & $(9.59)$ \\
\hline $3+$ & $\begin{array}{ll}0 & (0.00)\end{array}$ & $(0.00)$ & $(0.00)$ \\
\hline Total & $42(100.00)$ & $104(100.00)$ & $146(100.00)$ \\
\hline
\end{tabular}

HER2, human epidermal growth factor receptor 2. 
$\mathbf{A}$

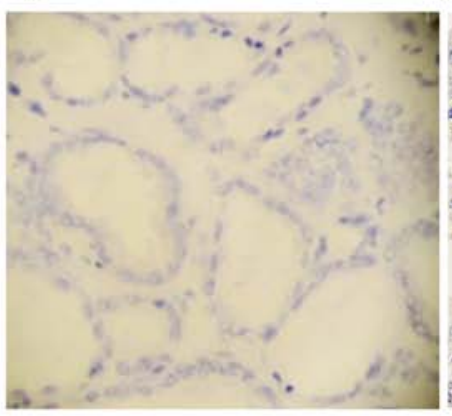

B

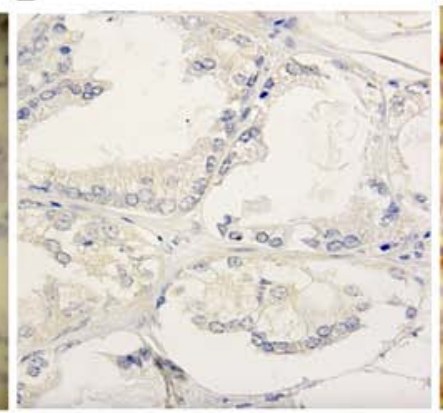

C

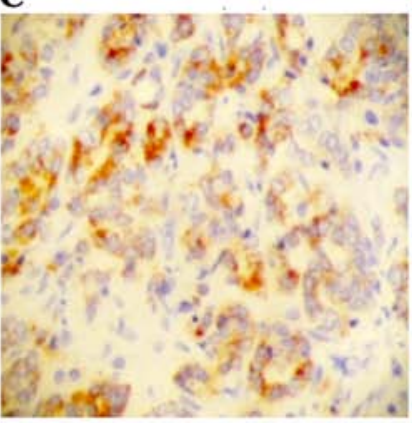

D

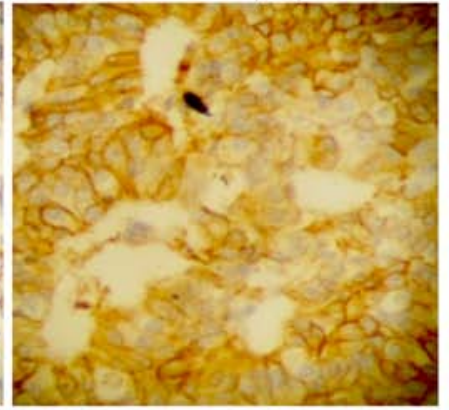

Figure 1. HER2 protein expression examined using anti-HER2 antibody A0485. (A) Absence of staining (0; negative control). (B) Faint/barely perceptible membrane staining detected in $>10 \%$ of the tumor cells. Cells were stained in only part of the membrane (1+). (C) Weak to moderate complete membrane staining observed in $>10 \%$ of tumor cells (2+). (D) Strong, complete membrane staining observed in $>10 \%$ of the tumor cells (positive control; $3+$ ). All magnifications are x200. HER2, human epidermal growth factor receptor 2.

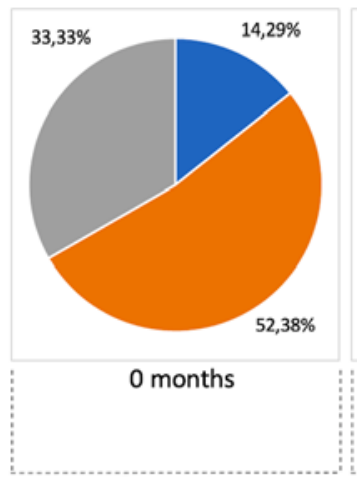

Group 1

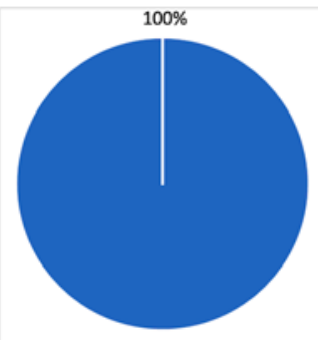

1 - 3 months

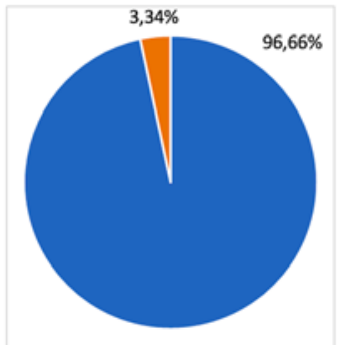

4 - 6 months

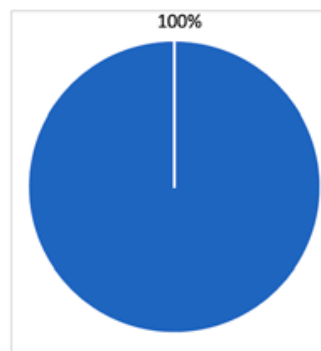

7-9 months

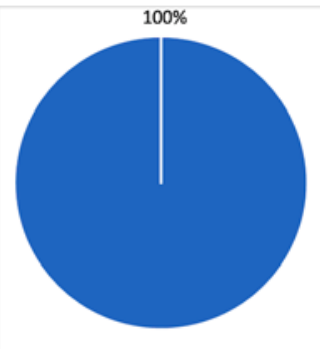

10 months or more

blocking time

Group 2

- DAKO 0 DAKO $1+$ DAKO $2+$

Figure 2. Expression of HER2 in patient group 1 and patient group 2 over time. In group 2, HER2 expression was subdivided into periods of exposure to neoadjuvant cyproterone acetate. A short period of neoadjuvant ADT suppressed HER2 expression. Dako 0, 1+ and 2+ refer to the graded relative intensities of staining. HER2, human epidermal growth factor receptor 2.

margin, and T stage had no significant effect on HER 2 expression $(\mathrm{P}>0.05)$ (Table III).

When comparing both groups, the univariate regression analysis indicated that perineural invasion, PSA, ISUP, angiolymphatic invasion, margin, $\mathrm{T}$ stage, and neoadjuvant ADT correlated with HER 2 expression. Nevertheless, ordinal regression analysis, including all cited variables, indicated a significant effect on HER2 expression only for neoadjuvant ADT $(\mathrm{P}<0.001)$. Similarly, regression analysis indicated a statistically significant effect of neoadjuvant ADT alone on HER2 expression $(\mathrm{OR}=0.01 ; 95 \% \mathrm{CI}: 0.00$. 0.02; $\mathrm{P}<0.001)$ (Table IV).

\section{Discussion}

The epidermal growth factor receptor (EGFR) family consists of four members: EGFR/ErbB1, HER2/ErbB2, HER3/ErbB3, and HER4/ErbB4. These are activated by ligand binding (except for HER2), followed by dimerization and phosphorylation (16). HER 2 is the preferred dimerization partner for EGFR, and both regulate cell proliferation, differentiation, angiogenesis, and survival (17). Nevertheless, the role of ErbB-2 vs. EGFR in androgen-stimulated proliferation is still not fully understood; this is partially due to the lack of suitable cell models (18). In the present study, we evaluated, for the first time, the effect of neoadjuvant ADT on HER2 expression.

According to our results, the expression of HER 2 occurred at distinct levels in a significant number of cases and was not associated with any prognostic factors. Various immunohistochemical methods have been used to examine the relationship between HER2 expression and PCa. Significant heterogeneity in HER2 expression has been noted in these previous studies (19-21), which is partially explained by discrepancy between methods, lack of measurement standardization, and heterogeneity of PCa itself (22). An important example is the study by Sanchez et al, who used two different evaluation techniques: The standard and modified HercepTest ${ }^{\mathrm{TM}}$ (23). This approach was necessary to improve the quality of HER2 analysis in patients with PCa. HER2 overexpression was found to be related to tumor stage and Gleason score. Our decision to use the standard HercepTest ${ }^{\mathrm{TM}}$ as a means of immunohistochemical interpretation was based on the literature and availability of kits in our institution's laboratories.

The introduction of neoadjuvant ADT was sufficient to suppress HER2 expression $(\mathrm{P}<0.001)$. This suppression was so relevant that individuals who received neoadjuvant ADT 
Table III. Univariate and multivariate ordinal logistic regression for HER2 expression in group 1.

\begin{tabular}{|c|c|c|c|c|}
\hline \multirow[b]{2}{*}{ Parameter } & \multicolumn{2}{|c|}{ Univariate regression } & \multicolumn{2}{|c|}{ Multivariate regression } \\
\hline & Odds ratio $(95 \% \mathrm{CI})$ & $\mathrm{P}$-value & Odds ratio $(95 \% \mathrm{CI})$ & P-value \\
\hline Age & $1.00(0.93-1.09)$ & 0.924 & - & - \\
\hline Perineural invasion & & & & 0.134 \\
\hline No & Reference & - & Reference & \\
\hline Yes & $0.81(0.25-2.65)$ & 0.731 & $0.33(0.0-1.41)$ & \\
\hline PSA & $1.07(0.87-1.33)$ & 0.511 & $1.04(0.81-1.34)$ & 0.733 \\
\hline \multicolumn{5}{|l|}{ ISUP } \\
\hline $1-2$ & Reference & - & Reference & - \\
\hline $3-5$ & $5.33(1.33-21.27)$ & 0.018 & $1.26(0.30-5.33)$ & 0.757 \\
\hline \multicolumn{5}{|l|}{ Angiolymphatic invasion } \\
\hline No & Reference & - & Reference & - \\
\hline Yes & $3.38(0.96-11.90)$ & 0.058 & $3.87(0.81-1.34)$ & 0.090 \\
\hline \multicolumn{5}{|l|}{ Surgical margins } \\
\hline No & Reference & - & Reference & - \\
\hline Yes & $2.76(0.82-9.31)$ & 0.102 & $2.19(0.54-8.83)$ & 0.271 \\
\hline \multicolumn{5}{|l|}{$\mathrm{T}$ stage } \\
\hline $\mathrm{T} 1-\mathrm{T} 2 \mathrm{~A}$ & Reference & - & Reference & - \\
\hline $\mathrm{T} 2 \mathrm{~B}$ & $1.00(0.06-15.31)$ & 0.999 & $0.86(0.05-14.70)$ & 0.918 \\
\hline$>\mathrm{T} 2 \mathrm{C}$ & $1.97(0.25-15.28)$ & 0.514 & $0.97(0.10-9.36)$ & 0.980 \\
\hline \multicolumn{5}{|l|}{ Diabetes } \\
\hline No & Reference & - & - & - \\
\hline Yes & $1.40(0.17-11.89)$ & 0.755 & - & - \\
\hline \multicolumn{5}{|l|}{ Hypertension } \\
\hline No & Reference & - & - & - \\
\hline Yes & $0.48(0.15-1.60)$ & 0.236 & - & - \\
\hline \multicolumn{5}{|l|}{ Smoking } \\
\hline No & Reference & - & - & - \\
\hline Yes & $1.45(0.30-7.07)$ & 0.645 & - & - \\
\hline \multicolumn{5}{|l|}{ Ethnicity } \\
\hline White & Reference & - & - & - \\
\hline Black & $2.23(0.29-17.23)$ & 0.443 & - & - \\
\hline Mixed ethnic ancestries & $0.76(0.22-2.61)$ & 0.666 & - & - \\
\hline
\end{tabular}

ISUP, International Society of Urological Pathology. HER2, human epidermal growth factor receptor 2.

had a 0.01 chance of HER2 expression compared to individuals who did not receive neoadjuvant $\mathrm{ADT}(\mathrm{OR}=0.01$; 95\% CI, 0.00, 0.02; P<0.001). Similarly, Muniyan et al observed that a HER2 inhibitor blocked androgen-induced activation and cell growth (24). These results are consistent with previous observations that HER 2 activation plays an essential role in regulating the androgen-stimulated proliferation of PCa cells (25). This pharmacological inhibition revealed that basal and androgen-induced ERK1/2 and p38 MAPK were significantly inhibited, which correlated with abolished cell growth. In our study, the suppression of HER2 caused by neoadjuvant ADT occurred as soon as one month after the initiation of therapy and was maintained thereafter. This suppression seemed to be maintained throughout the period that PCa was shown to be sensitive to hormone therapy.

We observed a higher percentage of HER2 expression in group $1(85.7 \%)$. A significant impact of neoadjuvant ADT was noted; only $1 \%$ of group 2 patients presented with HER2 expression. In addition, the effect was noted regardless of the time of analysis (1-24 months). Even a short period of neoadjuvant ADT suppressed HER2 expression. The study results highlight an exciting correlation between HER2, PCa, and ADT.

Interestingly, Chen et al demonstrated that dual inhibition of EGFR/HER2 with ADT resulted in the apoptosis of PCa cells (26). This could be an alternative, especially for castration-resistant prostate cancer (CRPC). In another study, 
Table IV. Univariate and multivariate ordinal logistic regression for HER2 expression in all groups.

\begin{tabular}{|c|c|c|c|c|}
\hline \multirow[b]{2}{*}{ Parameter } & \multicolumn{2}{|c|}{ Univariate regression } & \multicolumn{2}{|c|}{ Multivariate regression } \\
\hline & Odds ratio $(95 \% \mathrm{CI})$ & P-value & Odds ratio $(95 \% \mathrm{CI})$ & P-value \\
\hline Age & $0.99(0.94-1.04)$ & 0.733 & - & - \\
\hline \multicolumn{5}{|l|}{ Perineural invasion } \\
\hline No & Reference & - & Reference & - \\
\hline Yes & $2.15(1.01-4.54)$ & 0.046 & $0.31(0.08-1.28)$ & 0.106 \\
\hline PSA & $0.88(0.81-0.96)$ & 0.003 & $0.96(0.81-1.15)$ & 0.694 \\
\hline \multicolumn{5}{|l|}{ ISUP } \\
\hline $1-2$ & Reference & - & Reference & - \\
\hline $3-5$ & $3.81(1.74-8.33)$ & 0.001 & $1.73(0.45-6.68)$ & 0.425 \\
\hline \multicolumn{5}{|l|}{ Angiolymphatic invasion } \\
\hline No & Reference & - & Reference & - \\
\hline Yes & $4.71(2.04-10.86)$ & $<0.001$ & $3.43(0.78-15.16)$ & 0.104 \\
\hline \multicolumn{5}{|l|}{ Surgical margins } \\
\hline No & Reference & - & Reference & - \\
\hline Yes & $7.54(3.21-17.75)$ & $<0.001$ & $1.88(0.50-7.10)$ & 0.349 \\
\hline \multicolumn{5}{|l|}{ T stage } \\
\hline $\mathrm{T} 1-\mathrm{T} 2 \mathrm{~A}$ & Reference & - & Reference & - \\
\hline $\mathrm{T} 2 \mathrm{~B}$ & $0.76(0.14-4.07)$ & 0.413 & $0.71(0.06-8.98)$ & 0.790 \\
\hline$>\mathrm{T} 2 \mathrm{C}$ & $5.04(1.41-18.02)$ & 0.013 & $1.35(0.17-10.64)$ & 0.776 \\
\hline \multicolumn{5}{|l|}{ Neoadjuvant ADT } \\
\hline No & Reference & - & Reference & - \\
\hline Yes & $0.01(0.00-0.01)$ & $<0.001$ & $0.01(0.00-0.02)$ & $<0.001$ \\
\hline \multicolumn{5}{|l|}{ Diabetes } \\
\hline No & Reference & - & - & - \\
\hline Yes & $2.76(0.60-12.78)$ & 0.193 & - & - \\
\hline \multicolumn{5}{|l|}{ Hypertension } \\
\hline No & Reference & - & - & - \\
\hline Yes & $2.61(1.20-5.67)$ & 0.016 & - & - \\
\hline \multicolumn{5}{|l|}{ Smoking } \\
\hline No & Reference & - & - & - \\
\hline Yes & $1.82(0.63-5.24)$ & 0.268 & - & - \\
\hline \multicolumn{5}{|l|}{ Ethnicity } \\
\hline White & Reference & - & - & - \\
\hline Black & $3.79(0.96-14.98)$ & 0.057 & - & - \\
\hline Mixed ethnic ancestries & $2.92(1.30-6.58)$ & 0.010 & - & - \\
\hline
\end{tabular}

ADP, androgen deprivation therapy; HER2, human epidermal growth factor receptor 2; ISUP, International Society of Urological Pathology.

Di Lorenzo et al observed a significant association between HER2, high levels of PSA, and a high Gleason score in patients with metastatic CRPC, contributing to the hypothesis of the association between HER2 and PCa aggressiveness. $\mathrm{PCa}$ recurrence also correlated significantly with c-erB2 levels in $60 \%$ of cases (27).

Significant efforts have been made to determine whether neoadjuvant treatment improves clinical outcomes in PCa (27). For radiation therapy, numerous studies have shown benefits with the addition of neoadjuvant, concurrent, and adjuvant ADT in treating intermediate- and high-risk diseases $(28,29)$.
In contrast, the benefits of neoadjuvant therapy before RP (both ADT and chemotherapy) have not yet been determined. In addition, no significant improvement in progression-free survival and overall survival (OS) has been demonstrated in several trials (30). Despite this, neoadjuvant therapy before RP provides a unique opportunity to clarify the effects of treatment on the tumor microenvironment. Access to material from an old study in which patients underwent neoadjuvant hormone therapy offered a unique opportunity to study the effects of this type of treatment on HER2 expression; this is the reason why we included group 2 patients in this study. The 
suppression of HER2 observed in our study may be one of the mechanisms related to the response of tumors to ADT.

Some studies have suggested that HER 2 acts as a co-receptor in the cell response mediated by HER substrates (31-33). In addition, overexpression of HER 2 could increase the rate of cell transformation, one of the pathways involved in castration-resistant prostate adenocarcinoma. The specific activation of HER2 induces many independent signaling pathways, such as phospholipase C (PLC), phosphatidylinositol 3-kinase (PI3K), the JAK-STAT pathway, mitogen-activated protein kinases (MAPKs), and proteins activated by stress (27). These pathways activate proto-oncogenes such as c-fos, c-jun, and c-Src, which could lead to cell proliferation even in the absence of testosterone.

Signaling of the PI3K pathway by HER 2 also induces phosphorylation and inactivation of glycogen synthase kinase-3 (GSK3), resulting in increased nuclear levels of $\beta$-catenin, which in turn increases the activity of the androgen receptor (AR) and, consequently, stimulates the growth and survival of prostate cells. These findings delineate the mechanism by which HER2 and AR regulate the androgen pathway during prostate cell growth and survival (34).

In metastatic $\mathrm{PCa}$, circulating levels of HER2 have often been used as predictive markers of progression $(35,36)$. Jathal et al demonstrated that the failure of lapatinib in clinical trials of CRPC was due to its ability to significantly increase HER2 levels, which consequently led to increased protein synthesis rates. This resulted in the accumulation of excess HER2 in the plasma membrane, the formation of EGFR/HER2 dimers, and the transmission of signals to downstream targets that prevent loss of cell viability (36). Similarly, Tome-Garcia et al demonstrated that overexpression of the constitutively activated form of HER2 increases the metastatic potential of androgen-insensitive human PCa cell lines, but not of androgen-sensitive PCa cell lines (37). All these results can lead to the hypothesis that the moment of transformation of PCa in CRPC could be correlated with the moment of increased HER 2 expression after inhibition by ADT.

Future studies will examine whether suppression of HER2 transcription results in the cellular transformation of $\mathrm{PCa}$, mainly in CRPC. The data reported herein suggest a possible association between ADT and the inhibition of HER2 expression while the tumor was hormone-sensitive.

Our study has certain limitations. First, as in several other studies, we performed immunohistochemical analysis to evaluate HER2 expression in prostate specimens. However, while immunohistochemistry has an established track record for evaluating the expression of HER2 in breast cancer, it has not been used as definitively in PCa. The HerceptTest ${ }^{\mathrm{TM}}$ technique we used has specific instructions only for breast and gastric cancers, and not PCa. In addition, it did not show classic HER2 overexpression (3+) in any of the 146 cases studied. According to the HercepTest ${ }^{\mathrm{TM}}$ Interpretation Manual, the specific result 'HER2 +2' could be analyzed later with fluorescent in situ hybridization (FISH), which was not available in our laboratories (13). The use of FISH has also been suggested to solve the potential problem of inconsistent results whenever different antibodies are used in immunohistochemical testing. Another limitation was the use of medications for androgen deprivation. Despite these limitations, which could limit the clinical significance of our findings, our material is unique and provides valuable insights for research purposes, as well as suggesting possible directions for further research using different methods, such as FISH.

The data reported here suggest a possible association between testosterone-suppressing hormone therapy and inhibition of HER2 receptor expression.

\section{Acknowledgements}

Not applicable.

\section{Funding}

No funding was received.

\section{Availability of data and materials}

The datasets used and analyzed during the present study are available from the corresponding author upon reasonable request.

\section{Authors' contributions}

All authors contributed to data collection and analysis. GAP, FK, MGDC and LHSS drafted the manuscript. CLP, TFNL, MLW, NMC, MTM and SG edited the manuscript. All authors have read and approved the final version of the manuscript. GAP and FK confirm the authenticity of all the raw data.

\section{Ethics approval and consent to participate}

The present study was approved by the Ethics Committee of Centro Universitario FMABC and Santa Casa of São Paulo Hospital (approval nos. 84427718.0.0000.0082 and 06937412.0.1001.0082, respectively). Written informed consent was obtained from all patients.

\section{Patient consent for publication}

Not applicable.

\section{Competing interests}

The authors declare that they have no competing interests.

\section{References}

1. Rimawi MF, Mayer IA, Forero A, Nanda R, Goetz MP, Rodriguez AA, Pavlick AC, Wang T, Hilsenbeck SG, Gutierrez C, et al: Multicenter phase II study of neoadjuvant lapatinib and trastuzumab with hormonal therapy and without chemotherapy in patients with human epidermal growth factor receptor 2-overexpressing breast cancer: TBCRC 006. J Clin Oncol 31: 1726-1731, 2013.

2. Koeppen HK, Wright BD, Burt AD, Quirke P, McNicol AM, Dybdal NO, Sliwkowski MX and Hillan KJ: Overexpression of HER2/neu in solid tumours: An immunohistochemical survey. Histopathology 38: 96-104, 2001.

3. Slamon DJ, Godolphin W, Jones LA, Holt JA, Wong SG, Keith DE, Levin WJ, Stuart SG, Udove J, Ullrich A, et al: Studies of the HER-2/neu proto-oncogene in human breast and ovarian cancer. Science 244: 707-712, 1989. 
4. Cobleigh MA, Vogel CL, Tripathy D, Robert NJ, Scholl S, Fehrenbacher L, Wolter JM, Paton V, Shak S, Lieberman G and Slamon DJ: Multinational study of the efficacy and safety of humanized anti-HER2 monoclonal antibody in women who have HER2-overexpressing metastatic breast cancer that has progressed after chemotherapy for metastatic disease. J Clin Oncol 17: 2639-2648, 1999.

5. Neto AS, Tobias-Machado M, Wroclawski ML, Fonseca FL, Teixeira GK, Amarante RD, Wroclawski ER and Del Giglio A: Her-2/neu expression in prostate adenocarcinoma: A systematic review and meta-analysis. J Urol 184: 842-850, 2010.

6. Minner S, Jessen B, Stiedenroth L, Burandt E, Köllermann J, Mirlacher M, Erbersdobler A, Eichelberg C, Fisch M, Brümmendorf TH, et al: Low level HER2 overexpression is associated with rapid tumor cell proliferation and poor prognosis in prostate cancer. Clin Cancer Res 16: 1553-1560, 2010.

7. Carrión-Salip D, Panosa C, Menendez JA, Puig T, Oliveras G, Pandiella A, De Llorens R and Massaguer A: Androgen-independent prostate cancer cells circumvent EGFR inhibition by overexpression of alternative HER receptors and ligands. Int J Oncol 41: 1128-1138, 2012.

8. Craft N, Shostak Y, Carey M and Sawyers CL: A mechanism for hormone-independent prostate cancer through modulation of androgen receptor signaling by the HER-2/neu tyrosine kinase. Nat Med 5: 280-285, 1999.

9. Miyamoto H, Hernandez DJ and Epstein JI: A pathological reassessment of organ-confined, Gleason score 6 prostatic adenocarcinomas that progress after radical prostatectomy. Hum Pathol 40: 1693-1698, 2009.

10. Kobayashi M, Ishida H, Shindo T, Niwa S, Kino M, Kawamura K, Kamiya N, Imamoto T, Suzuki H, Hirokawa Y, et al: Molecular analysis of multifocal prostate cancer by comparative genomic hybridization. Prostate 68: 1715-1724, 2008.

11. Lepor H and Donin NM: Gleason 6 prostate cancer: Serious malignancy or toothless lion? Oncology (Williston Park) 28 16-22, 2014.

12. Korkes F, de Castro MG, de Cassio Zequi S, Nardi L, Del Giglio A and de Lima Pompeo AC: Hyaluronan-mediated motility receptor (RHAMM) immunohistochemical expression and androgen deprivation in normal peritumoral, hyperplasic and neoplastic prostate tissue. BJU Int 113: 822-829, 2014.

13. Espinoza $\mathrm{F}$ and Thompson $\mathrm{J}$ : HercepTest ${ }^{\mathrm{TM}}$ interpretation manual. Dako, 2010.

14. Egevad L, Delahunt B, Srigley JR and Samaratunga H: International society of urological pathology (ISUP) grading of prostate cancer-an ISUP consensus on contemporary grading. APMIS 124: 433-435, 2016.

15. Brierley JD, Gospodarowicz MK and Wittekind C (eds): TNM classification of malignant tumors. UICC International Union Against Cancer, 2017.

16. Hynes NE and Lane HA: ERBB receptors and cancer: The complexity of targeted inhibitors. Nat Rev Cancer 5: 341-354, 2005.

17. Yarden $\mathrm{Y}$ and Sliwkowski MX: Untangling the ErbB signalling network. Nat Rev Mol Cell Biol 2: 127-137, 2001.

18. Di Lorenzo G, Tortora G, D'Armiento FP, De Rosa G, Staibano S, Autorino R, D'Armiento M, De Laurentiis M, De Placido S, Catalano G, et al: Expression of epidermal growth factor receptor correlates with disease relapse and progression to androgen-independence in human prostate cancer. Clin Cancer Res 8: 3438-3444, 2002.

19. Rao K, Gaughan L, Robson $\mathrm{C}$ and McCracken S: The role of the HER 2 and HER 3 in prostate cancer and their potential as therapeutic targets. Eur J Cancer 61 (Suppl 1): S177, 2016.

20. Baek KH, Hong ME, Jung YY, Lee CH, Lee TJ, Park ES, Kim MK, Yoo JH and Lee SW: Correlation of AR, EGFR, and HER 2 expression levels in prostate cancer: Immunohistochemical analysis and chromogenic in situ hybridization. Cancer Res Treat 44: 50-56, 2012.

21. Yan M, Schwaederle M, Arguello D, Millis SZ, Gatalica Z and Kurzrock R: HER2 expression status in diverse cancers: Review of results from 37,992 patients. Cancer Metastasis Rev 34: $157-164,2015$

22. Lara PN Jr, Meyers FJ, Gray CR, Edwards RG, Gumerlock PH, Kauderer C, Tichauer G, Twardowski P, Doroshow JH and Gandara DR: HER-2/neu is overexpressed infrequently in patients with prostate carcinoma. Results from the California cancer consortium screening trial. Cancer 94: 2584-2589, 2002.
23. Sanchez KM, Sweeney CJ, Mass R, Koch MO, Eckert GJ, Geary WA, Baldridge LA, Zhang S, Eble JN and Cheng L: Evaluation of HER-2/neu expression in prostatic adenocarcinoma: A requested for a standardized, organ specific methodology. Cancer 95: 1650-1655, 2002.

24. Muniyan S, Chen SJ, Lin FF, Wang Z, Mehta PP, Batra SK and Lin M-F: ErbB-2 signaling plays a critical role in regulating androgen-sensitive and castration-resistant androgen receptorpositive prostate cancer cells 27: 2261-2271, 2015.

25. Di Lorenzo G, Autorino R, De Laurentiis M, Cindolo L, D'Armiento M, Bianco AR and De Placido S: HER-2/neu receptor in prostate cancer development and progression to androgen independence. Tumori 90: 163-170, 2004.

26. Chen L, Mooso BA, Jathal MK, Madhav A, Johnson SD, van Spyk E, Mikhailova M, Zierenberg-Ripoll A, Xue L, Vinall RL, et al: Dual EGFR/HER2 inhibition sensitizes prostate cancer cells to androgen withdrawal by suppressing ErbB3. Clin Cancer Res 17: 6218-6228, 2011.

27. Meng TC, Lee MS and Lin MF: Interaction between protein tyrosine phosphatase and protein tyrosine kinase is involved in androgen-promoted growth of human prostate cancer cells. Oncogene 19: 2664-2677, 2000.

28. Bolla M, Van Tienhoven G, Warde P, Dubois JB, Mirimanoff RO, Storme G, Bernier J, Kuten A, Sternberg C, Billiet I, et al: External irradiation with or without long-term androgen suppression for prostate cancer with high metastatic risk: 10 -year results of an EORTC randomised study. Lancet Oncol 11: 1066-1073, 2010.

29. Denham JW, Steigler A, Lamb DS, Joseph D, Turner S, Matthews J, Atkinson C, North J, Christie D, Spry NA, et al: Short-term neoadjuvant androgen deprivation and radiotherapy for locally advanced prostate cancer: 10-year data from the TROG 96.01 randomised trial. Lancet Oncol 12: 451-459, 2011

30. Pendleton J, Pisters LL, Nakamura K, Anai S and Rosser CJ: Neoadjuvant therapy before radical prostatectomy: Where have we been? Where are we going? Urol Oncol 25: 11-18, 2007.

31. Wilson KJ, Gilmore JL, Foley J, Lemmon MA and Riese DJ II: Functional selectivity of EGF family peptide growth factors: Implications for cancer. Pharmacol Ther 122: 1-8, 2009.

32. Furrer D, Paquet $C$, Jacob $S$ and Diorio $C$ : The human epidermal growth factor receptor 2 (HER2) as a prognostic and predictive biomarker: Molecular insights into HER2 activation and diagnostic implications. Cancer Prognosis: pp11-13, 2018.

33. Ding L, Tian C, Feng S, Fida G, Zhang C, Ma Y, Ai G, Achilefu S and Gu Y: Small sized EGFR1 and HER2 specific bifunctional antibody for targeted cancer therapy. Theranostics 5: 378-398, 2015.

34. Tambo M, Higashihara E, Terado Y, Nutahara K and Okegawa T: Comparison of serum HER2/neu with immunohistochemical HER 2/neu expression for the prediction of biochemical progression in metastatic prostate cancer. Int J Urol 16: 369-374, 2009.

35. Domingo-Domenech J, Fernandez PL, Filella X Martinez-Fernandez A, Molina R, Fernandez E, Alcaraz A, Codony J, Gascon P and Mellado B: Serum HER2 extracellular domain predicts an aggressive clinical outcome and biological PSA response in hormone-independent prostate cancer patients treated with docetaxel. Ann Oncol 19: 269-275, 2008

36. Jathal MK, Steele TM, Siddiqui S, Mooso BA, D'Abronzo LS, Drake CM, Whang YE and Ghosh PM: Dacomitinib, but not lapatinib, suppressed progression in castration-resistant prostate cancer models by preventing HER2 increase. Br J Cancer 121: 237-248, 2019.

37. Tome-Garcia J, Li D, Ghazaryan S, Shu L and Wu L: ERBB2 increases metastatic potentials specifically in androgen-insensitive prostate cancer cells. PLoS One 9: e99525, 2014.

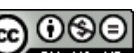

This work is licensed under a Creative Commons Attribution-NonCommercial-NoDerivatives 4.0 International (CC BY-NC-ND 4.0) License. 